Elsevier Editorial System(tm) for Fire Safety Journal Manuscript Draft

Manuscript Number: FISJ-D-12-00069R1

Title: A NASCENT EDUCATIONAL FRAMEWORK FOR FIRE SAFETY ENGINEERING

Article Type: Research Paper

Keywords: Fire; Safety; Engineering; Education; Competence

Corresponding Author: Prof. Luke A Bisby, BEng, MSc, PhD

Corresponding Author's Institution: University of Edinburgh

First Author: Michael Woodrow, MEng

Order of Authors: Michael Woodrow, MEng; Luke Bisby, BEng, MSc, PhD; Jose L Torero, PhD

Abstract: The growing need for fire safety engineering (FSE) design around the world has led to higher education degrees, many of which lack strong foundations in fundamental knowledge and are somewhat deficient in developing skills (application of knowledge) and appropriate attitudes (reflective assessment and synthesis of knowledge). This paper discusses how such programmes are delivering professionals to an FSE industry that has not yet adequately defined competence. Motivated by the need to have a new generation of leaders in FSE that can drive the field through the ongoing and necessary transition to performance-based design that it is currently experiencing, a one-week, intensive global technical leadership seminar was held at Edinburgh University, supported by The Lloyd's Register Educational Trust (LRET). The Seminar was aimed at reflecting on the content and methodology required in comprehensive university programmes capable of educating in design for fire safety in the built environment. Performance-based design for fire, in which prescriptive codes are simply a tool within a performance-based mindset, offers many important benefits but also has many acknowledged problems and risks; this paper argues that paramount among the problems is the way that we, as a global engineering profession, educate and nurture FSE professionals. It is argued that fire safety is a relatively immature discipline, thus it should be supported by holistic, purpose-centred education that places an emphasis on learning environments broadly focused on design. Technical (fundamental) knowledge is clearly critically important, but it should not be the driving force, and it should not eclipse the development of the skills and attitudes essential for the future survival of fire safety engineering as a distinct, competency-based engineering discipline. 


\section{A NASCENT EDUCATIONAL FRAMEWORK FOR MODERN FIRE SAFETY ENGINEERING}

Michael Woodrow, Luke Bisby and Jose L Torero

The BRE Centre for Fire Safety Engineering, School of Engineering, University of Edinburgh, UK

\section{RESEARCH HIGHLIGHTS}

Note that this paper is not a tradition research paper; rather it is focused on education in fire safety engineering (FSE). Nonetheless, the following are the highlights:

- FSE programs lack strong foundations in fundamental knowledge

- FSE programs are deficient in providing skills and developing attitudes

- The FSE industry has not yet adequately defined competence

- FSE is an immature discipline and should support purpose-centred education

- The FSE profession must generate and promote exemplar people and projects 


\title{
A NASCENT EDUCATIONAL FRAMEWORK FOR FIRE SAFETY ENGINEERING
}

\author{
Michael Woodrow, Luke Bisby and Jose L Torero \\ The BRE Centre for Fire Safety Engineering, School of Engineering, University of Edinburgh, UK
}

\begin{abstract}
The growing need for fire safety engineering (FSE) design around the world has led to higher education degrees, many of which lack strong foundations in fundamental knowledge and are somewhat deficient in developing skills (application of knowledge) and appropriate attitudes (reflective assessment and synthesis of knowledge). This paper discusses how such programmes are delivering professionals to an FSE industry that has not yet adequately defined competence. Motivated by the need to have a new generation of leaders in FSE that can drive the field through the ongoing and necessary transition to performance-based design that it is currently experiencing, a one-week, intensive global technical leadership seminar was held at Edinburgh University, supported by The Lloyd's Register Educational Trust (LRET). The Seminar was aimed at reflecting on the content and methodology required in comprehensive university programmes capable of educating in design for fire safety in the built environment. Performance-based design for fire, in which prescriptive codes are simply a tool within a performance-based mindset, offers many important benefits but also has many acknowledged problems and risks; this paper argues that paramount among the problems is the way that we, as a global engineering profession, educate and nurture FSE professionals. It is argued that fire safety is a relatively immature discipline, thus it should be supported by holistic, purpose-centred education that places an emphasis on learning environments broadly focused on design. Technical (fundamental) knowledge is clearly critically important, but it should not be the driving force, and it should not eclipse the development of the skills and attitudes essential for the future survival of fire safety engineering as a distinct, competency-based engineering discipline.
\end{abstract}

\subsection{INTRODUCTION \& BACKGROUND}

The built environment is evolving rapidly. Modern buildings are increasingly designed to be energy efficient, with sustainability considerations and structural optimisation making structures lighter and leaner than ever before. Novel construction techniques and the use of innovative building materials and systems are resulting in the design of highly unconventional building shapes and sizes [1]. In addition, the introduction of novel sensor and network technologies is posing a challenge to conventional design techniques while offering a new array of opportunities for synergy between the different technologies that can result in a more integrated approach to building management [2]. As a result, fire safety design, assessment, implementation, and/or operation of these modern buildings is becoming out of date. So-called prescriptive design for fire, which has traditionally been used, is based on a set of codified rules which enable engineering professionals to blindly develop 'designs' with only basic fire safety engineering (FSE) competence. The current prescriptive codes are based on knowledge sometimes several decades old and/or derived from buildings that were different in a multitude of ways from modern ones. Fire safety engineering thus adopted performance-based design in the 1990's [3,4] however its implementation has drifted towards the concept of an unquantified level of safety which is 'equivalent' to the code, rather than towards true, engineering-based performance assessment [5]. Thus, notwithstanding many examples of performance-based design for fire implemented globally, the prescriptive framework for design remains in the majority of situations.

The last two decades have given us many examples of largely or wholly code-compliant buildings which have been destroyed by fire; for example World Trade Centre 7, New York (2001); Technical University of Delft (2008), and the TVCC Building, Beijing (2008). All were code-compliant buildings which were unable to respond with their intended performance - including structural behaviour - despite the fact that they could not withstand a burnout fire (as intended, however with an acceptable level of risk, by the fundamental tenets of fire safety design [6]). It seems clear that nature of the problem over the years has steadily, fundamentally, and unknowingly changed. Thus, traditional fire safety practice (and in many cases practitioners) are no longer fully equipped to satisfy the needs of the built environment that drivers other than fire (e.g. energy, sustainability, architectural innovation, structural optimization, etc.) continue to create.

While the above paragraph suggests a potential problem, there is also a tremendous opportunity. If fire safety engineering design can find ways to synergize with other disciplines that drive the construction industry, 
FSE could experience a rapid and positive evolution consistent with other engineering disciplines. For this to occur it is essential for FSE as a profession to evolve towards true performance-based design. While it must be recognized that the many sectors involved in FSE need to evolve in a consistent manner, this will never happen if the evolution does not start within the educational systems charged with delivering the next generation of fire safety engineers. There is a clear need for educational 'programs' which are capable of pushing forward the boundaries of FSE, rather than simply perpetuating the status quo. This must begin within the universities; however it must clearly not end upon graduation. A generation of technical leaders is needed who can affect industry-wide change, transforming FSE into a proactive, rational and holistic discipline based on a rigorous scientific understanding of the key issues of today and tomorrow. Through appropriate and ongoing FSE education, a cohort of fire safety professionals can be generated who share a common language and who, in synergy with other disciplines, can conceive and materialise the future built environment.

The growing need for FSE design around the world has led to a proliferation of remedial short courses and higher education degrees based largely on technology rather than design; many of these lack a strong foundation in knowledge and are deficient in improving skills and developing appropriate attitudes in their graduates. It is our contention that such programs are able to exist because they are delivering professionals into an industry that has not (yet) adequately defined competence. Furthermore, this lack of a competence definition is confusing other professionals with whom fire safety engineers must collaborate; this isolates the FSE profession. The transformation of FSE is therefore slow, mistakes are made, and hidden, poorly quantified risks are taken. There is confusion about the requisite training and experience needed to perform adequate performance-based design for fire. Indeed, in some jurisdictions (e.g. Norway) regulators are turning their backs on performance-based design and retreating into prescriptive design, citing the fact that the engineers are not capable, their regulatory process is not good enough, and performance-based design doesn't work in practice. Similar moves are underway in New Zealand, which has historically been at the forefront of promoting performance-based building codes but is now seeking to prescribe performance [7].

Could it be that the codes are not the problem? Could it be that better education could help FSE to move forward into innovation rather than retreat back into prescription?

Motivated by the need to have a new generation of leaders in FSE that can drive the field through the transition it is currently experiencing, The BRE Centre for Fire Safety Engineering at the University of Edinburgh, with financial support provided by The Lloyd's Register Educational Trust (LRET), held a five day, intensive global technical leadership seminar on FSE education. The Seminar was aimed at reflecting on both the content and methodology required in a comprehensive university training program that is capable of educating engineers, but also architects, building regulators, and the fire services in holistic approaches to design for fire safety in the modern built environment - a program with the potential to germinate the transformational path needed by $21^{\text {st }}$ century FSE. Some of the world's most influential and innovative members of the FSE community were invited to Edinburgh, along with an international group of exceptional undergraduate and postgraduate students, with the intent to bring together leaders of today with leaders of tomorrow to define and invest in a positive, constructive, and coherent path for different areas of critical importance to the field; to debate the educational needs for the creation of a discipline in which a dialogue among truly competent professionals becomes the norm.

The LRET Seminar also fits within the scope of a PhD project on FSE education that is currently underway at the University of Edinburgh. This 'white paper' presents the initial outcomes of the seminar within the context of the nascent educational framework that is being developed.

\subsection{Disclaimer}

In order to critique the present state of education in any academic discipline with a view to making improvements and charting a path for a successful future, it is worthwhile to look at the strengths, weaknesses, opportunities, and threats to the discipline. Due to limited space, we have chosen to focus on the weaknesses and threats for FSE Education. We would like to stress that there are of course many strengths of, and opportunities for, FSE globally, and it is important to state at the outset that our intent is to be constructively critical. 


\subsection{University Education}

The current paper is focused on university education. Within the context of FSE education it is worth asking what the fundamental purpose of a university education is. This is an age-old and essentially unanswerable question; one which has been debated over the decades, particularly with respect to university education for applied disciplines such as engineering. University education seeks to achieve a balance between short-term and long-term goals, between training (knowledge) and education (skills and attitudes), between vocational and general, between a university degree and the need for lifelong learning, and between the capabilities of students to ably perform professional tasks immediately upon graduation and their ability to develop themselves and their discipline beyond its current boundaries [8].

Clearly, there is a place in all engineering disciplines both for vocationally trained 'technicians' who can use design tools and codes and/or education geared more toward holistically educated 'engineers' who understand and can extend design tools and codes. However, a key motivator for holding the LRET Seminar was an emerging concern within the built environment design community that education in FSE is tending too heavily towards training technicians and not enough towards educating engineers; that the discipline is immature and has not yet clearly defined what distinguishes a fire safety engineer from a fire safety technician; and that strategic thinking is urgently needed on this issue if the discipline is to truly stand equally among other acknowledged disciplines such as structural or mechanical engineering.

In the current paper we are interested in the future leaders of the fire safety engineering discipline, and as such our focus is on the necessary skills and attitudes that an FSE education should provide (i.e. on the methodologies of education that are likely to develop these), rather than on knowledge (i.e. technical content). The technical content of a fire safety engineering degree is briefly discussed later in the paper but has previously been reported in great detail [e.g. 9]. The fundamental goal herein is to initiate a global discussion of the way forward for FSE education, and hence the way forward for the FSE discipline such that the necessary effort and investment in education are made.

\subsection{The Fundamentals}

The less established a technical field is, the more true education (rather than training) needs to be given priority. The fundamentals of a subject can be defined as knowledge that is indivisible, and can be assumed to be valid for all cases. Examples include gravity, Newton's laws, and Pythagoras' law. Students must learn the fundamentals of a subject before they are capable of using and understanding more complex systems or tools (i.e. skills). Students who truly learn the fundamentals will be able to support engineered solutions using knowledge that is almost irrefutable.

If students leave university and go on to become performance-based designers, they will surely encounter unique problems without pre-defined solutions. Existing solutions involving complex tools contain implicit, often unknown assumptions that may not be appropriate in all cases. In a field such as FSE, which is in constant evolution, where solutions have not been optimized and where the existing problems require generation of entirely new solutions, the taught material might better be restricted to the fundamentals knowledge which is applicable in all situations [10].

In practice, a significant amount of non-fundamental knowledge (specific solutions) is necessary to resolve the required tasks. Thus, fundamental and non-fundamental knowledge coexist in an almost seamless manner in the design methods, in applied technologies, and in FSE design codes and engineering tools. Problems arise however, if fundamental knowledge is confused with specific knowledge; and without full contextual understanding of the problem, students will be inclined to falsely believe that any knowledge presented at a university is factual and applicable in all situations.

Acquired knowledge forms part of an individual's cognitive framework and therefore has context; but precisely what this context is will depend on the way in which that knowledge was acquired. Knowledge gained to answer one isolated question with no perceived relevance to the real world will render that knowledge useless in all but that one particular case. To gain full contextual understanding - the big picture - students must be able to explain the real-world relevance of all the knowledge they acquire at university; this requires development not only of knowledge, but also of skills and attitudes. 
In contrast to disciplinary knowledge, skills and attitudes are not acquired, but improved through practice. If graduates are to reach the level of skill required for true performance-based FSE design they must do engineering (either at university or under careful supervision during their formative years of professional design practice, or preferably both). The more authentic the learning environment, the more likely the students will be to develop skills and attitudes appropriate for industry [11].

\subsection{THE LRET GLOBAL TECHNICAL LEADERSHIP SEMINAR IN FSE}

In order to develop a balanced, global view of issues surrounding the future of FSE education, a five day residential seminar (i.e. think-tank) was held in June 2011 near Edinburgh (The $1^{\text {st }}$ Annual LRET Global Technical Leadership Seminar in FSE). A diverse group of current leading members of the FSE community was invited to attend, along with other international leaders in roles directly relevant to FSE and a competitively selected group of outstanding undergraduate and post-graduate FSE students. The full list of participants is given in Table 1, below.

Table 1 - LRET Global Technical Leadership Seminar in Fire Safety Engineering

\begin{tabular}{|c|c|c|c|}
\hline $\begin{array}{l}\text { Name } \\
\text { (order of } \\
\text { presentation) }\end{array}$ & Role & Organization & Presentation (if applicable) \\
\hline Michael Franklin & Director & $\begin{array}{l}\text { The Lloyd's Register Educational } \\
\text { Trust }\end{array}$ & Why The LRET Funded the Seminar \\
\hline Prof Jose Torero & $\begin{array}{l}\text { Director and Professor of } \\
\text { Fire Safety Engineering }\end{array}$ & $\begin{array}{l}\text { BRE Centre for Fire Safety } \\
\text { Engineering, UoE }\end{array}$ & $\begin{array}{l}\text { The Current State of Fire Safety Engineering } \\
\text { Education }\end{array}$ \\
\hline Peter Johnson & Principal and Fellow & Arup (Fire Australia) & The Needs of Industry / Consultancy \\
\hline Thouria Istephan & Partner & Fosters + Partners & The Needs of Architects \\
\hline Prof Bjorn Karlsson & Director & Iceland Construction Authority & $\begin{array}{l}\text { The Swedish Model - How Sweden Implemented } \\
\text { Change }\end{array}$ \\
\hline Dr Chris Lawless & Teaching Fellow & $\begin{array}{l}\text { Institute for the Study of Science, } \\
\text { Technology and Innovation, UoE }\end{array}$ & $\begin{array}{l}\text { Societal Barriers to Technological Knowledge } \\
\text { Transfer }\end{array}$ \\
\hline Kathleen Almand & Executive Director & $\begin{array}{l}\text { The Fire Protection Research } \\
\text { Foundation }\end{array}$ & The Evolution of Codes and Standards \\
\hline David Mallin & $\begin{array}{l}\text { Director, Community Fire } \\
\text { Safety }\end{array}$ & $\begin{array}{l}\text { Lothian and Borders Fire and Rescue } \\
\text { Service }\end{array}$ & How do we train people in the fire service today? \\
\hline Paul Jenkins & $\begin{array}{l}\text { Group Manager, Fire } \\
\text { Engineering Group }\end{array}$ & London Fire Brigade & Tomorrow's Needs of the Fire Service \\
\hline Dr Maria Garlock & Associate Professor & Princeton University & $\begin{array}{l}\text { Structural Engineering/Architecture/Fire Safety - } \\
\text { How are people educated at Princeton? }\end{array}$ \\
\hline Dr Peter Sunderland & Associate Professor & University of Maryland & Fire Protection Engineering Education in the USA \\
\hline David Crowder & Senior Consultant & BRE Fire and Security & Lessons Learned from Fire Incidents \\
\hline Sarah Higginson & MEng Student & University of Edinburgh & \multirow{5}{*}{ Proposals for the Way Forward } \\
\hline Eduardo Maciel & MSc Student & University of Edinburgh & \\
\hline Agustin Majdalani & PhD Candidate & University of Edinburgh & \\
\hline Cristian Maluk & PhD Candidate & University of Edinburgh & \\
\hline Ieuan Rickard & MEng Student & University of Edinburgh & \\
\hline Dr Luke Bisby & $\begin{array}{l}\text { Reader \& Senior Research } \\
\text { Fellow in Structures in Fire }\end{array}$ & University of Edinburgh & \multirow{2}{*}{$\begin{array}{l}\text { Conclusions and Discussions on the creation of a } \\
\text { White Paper (i.e. the current paper) }\end{array}$} \\
\hline Michael Woodrow & PhD Student & University of Edinburgh & \\
\hline Neal Butterworth & Associate Director & Arup (Fire UKMEA) & -- \\
\hline Dr Angus Law & Engineer & Arup (Fire UKMEA) & -- \\
\hline
\end{tabular}

The format for the Seminar essentially consisted of a series of presentations given by the participants. These were followed by breakouts and group discussions on the issues that were raised. Presentations were intended to discuss the roles and concerns of various relevant disciplines (e.g. academia, architecture, fire services, regulation, etc.) and to give thoughts on the current and future needs of the respective disciplines with respect to FSE education and advancement of the entire FSE field. The full program for the seminar is not included here; however the topics of the various presentations have been included in Table 1.

This paper thus represents an attempt by the authors to present a coherent and objective consolidation of the ideas, comments, and concerns raised by all the Seminar participants. However, some opposing views were obviously expressed and the views expressed in this paper should thus not be considered as the views of all participants. 


\subsection{STATE OF THE FSE FIELD}

In the 1970s, FSE began as a discipline of individuals capable of interpreting and rationally applying mostly prescriptive fire safety codes. The codes presented design solutions that, if applied correctly, offered a solution with an assumed 'guaranteed' acceptable level of safety. In parallel, a second group of professionals, mainly scientists, structured the underpinning science behind Fire Safety Engineering [12-16]. The acquired technical and scientific knowledge enabled a considerable evolution of the codes, the development of engineering tools (i.e. tests, analytical models, empirical (and semi-empirical) correlations, computer based models, etc.) and the increasing acceptance of performance-based design as a viable methodology.

Fire safety engineering, as are all engineering disciplines to varying extents, is by definition immature. Problems evolve with time and professionals have to accept that the knowledge available will, in many cases, be insufficient to definitively ensure a reliable, 'safe' design. Building codes and standards, and buildings designed to those regulatory documents, can only achieve a 'reasonable' or 'adequate' level of safety. There is no such thing as zero-risk or absolute safety. We set acceptable distances between buildings, we provide limited heights for spandrels to minimize the risk of vertical fire spread, and we set maximum travel distances to exits. However, we know in each case that fire spread and smoke filling can occur in a limited number of less likely scenarios, and people's lives may be lost as a result, but the risk is acceptably low. To make these requirements more stringent (greater safety) would make buildings more costly, and there is a community trade-off between risk and cost. In response, engineers have learned to accept their ignorance, to err on the side of caution, and to apply appropriate safety factors. Thus, the quantification of immaturity in a technical discipline is associated to some extent with safety factors and gaps of knowledge.

The size of the safety factor is intimately linked to our understanding of the problem, but the natural tendency is to reduce safety factors as far as is socially acceptable. For fire safety, the demand for optimised solutions (and thus reduced safety factors) has grown as structural design has evolved and other demands such as sustainability, novel materials, energy conservation and cost have become more important. Furthermore, modern construction practices are delivering new problems that in many cases have never been addressed. The gap between current knowledge and required knowledge for design is therefore growing, along with the demand for reduced safety factors. The optimisation process for fire safety now requires decisions and engineering judgement that might be beyond that which is available from a typical fire safety engineer. In other words FSE is at risk of losing maturity.

So what then, is the role of a fire safety engineer? Originally trained to interpret and apply prescriptive building code requirements or, more recently, to achieve some unquantified 'equivalent' level of safety, the fire safety engineer now works in a built environment which has evolved beyond the scope of prescriptive requirements and a new methodology has emerged: performance-based design.

The concept of performance-based design is straightforward - allow any design that can be proved, quantitatively to provide an acceptable level of safety. The definition of acceptable safety is the attainment of quantitative indicators (true performance goals/targets), which are deemed to provide the socially acceptable level of safety (e.g. structural design to withstand burnout, smoke levels not to reach tenability limits before evacuation is complete, etc.). The level of flexibility created by the new performance-based paradigm is its greatest strength, but perhaps also its greatest weakness. Performance-based design shifts the moral and legal responsibilities of producing fire-safe designs from large research and government organisations to individual engineers. The system has the potential to produce designs today that would otherwise take many years of research. On the other hand, if an individual engineer lacks skill, knowledge, competency awareness, or sound ethical principles the results could be disastrous. While the advantages and disadvantages of performance-based design are clear, it is essential to consider how a profession can undergo the transition in a way that emphasizes the advantages and minimizes the disadvantages.

The following current issues were identified by the Seminar participants as being key constraints on the current transition between prescriptive and performance-based design with a relevance to FSE education. 


\subsection{Inertia}

Despite the noted problems in the FSE community at present, the discipline nonetheless appears to be functioning adequately, and in many respects it is. It can be argued that change is needed, both within the FSE industry and within FSE education, but not everyone will agree. Nonetheless, the inertia of the current status quo represents a major constraint on reform. This has serious implications on accreditation, performance versus prescriptive design, and integration into the design team. Change is never easy, but the seminar participants generally agreed that it is particularly difficult to affect change in FSE. It was noted that there is a fear of obsolescence from many FSE practitioners; i.e. if more knowledgeable, scientific, holistic FSE design becomes the norm then one risks becoming irrelevant. The persisting reliance on prescriptive guidance (and regulation) also represents a major inertial constraint on advancing FSE design and education, since in many jurisdictions the conditions do not currently exist for highly trained graduates to apply advanced knowledge, skills, and attitudes in practice. Inertia can only be overcome by transformative thinking by many members of the FSE community.

\subsection{Measuring Performance}

While not explicitly an educational constraint, rather a constraint on the entire FSE discipline, it was repeatedly noted that measuring performance is difficult (if not impossible) in many FSE design situations. This is linked to an issue of quantifying acceptable levels of safety as a means of establishing compliance. It is difficult to establish an 'acceptable' or 'appropriate' level of safety against fire, and even more difficult to demonstrate or measure the performance of a given design. This is one reason why the education process in FSE needs to ensure a rational, scientific, and holistic approach to teaching FSE designers, so that they can competently and openly embrace all of the uncertainties that they will surely face in a performance-based environment.

\subsection{Isolation/Communication/Integration}

The FSE discipline is relatively small, isolated, and poorly integrated within the overall building design team. This can result in poor communication between FSE designers and other stakeholders in the design process, and in poorly conceived FSE merely being an add-on or 'value engineering' measure. Poor integration permeates into the engineering education community in that most engineering (civil, structural, mechanical, electrical) or architecture students are rarely exposed, even at surface level, to the goals and practice of FSE design. This is particularly problematic given the profound social and economic impacts that FSE has on designs across all areas of the built environment. Despite its small size, FSE needs to be better integrated into the education of all relevant stakeholders, at the very least in terms of providing a base awareness of the discipline and its fundamental goals.

\subsection{Competency Awareness}

Poor individual awareness of competence is a critical issue in the FSE community. Dunning et al. [17] provide a discussion of the sociological phenomenon known as competency awareness. The available research in this area clearly shows that people tend to hold overly favourable views of their abilities in their intellectual domains, and that as a consequence not only do they reach erroneous conclusions and make unfortunate choices, but their lack of competence robs them of the ability to recognize it. Poor competency awareness within FSE is partly a consequence of the small size of the discipline and the lack of support for initial or continuing education, which necessitates the utilization of poorly educated practitioners to fill available positions; partly a consequence of the lack of rigorous accreditation procedures for practitioners; partly a consequence of our reliance on prescriptive approaches to design, which permit (indeed promote) a lack of fundamental understanding of the principles upon which an integrated fire safety strategy should be based; and partly a consequence of educational programmes which support all of the above. Strong competency awareness must therefore be promoted and nurtured within the FSE educational system, and this can be best accomplished by focusing on fire safety science fundamentals rather than prescriptive compliance, and by creating a learning environment in which open-minded, student-led, studio style learning is the norm. This can also be encouraged by developing a strong and technically competent checking and approvals environment. 


\subsection{Education 'System' Issues}

Universities have been using certain educational systems for centuries; they have produced some excellent engineers and have gained approval from the relevant accrediting bodies. There are huge incentives to keep the status quo and use a standardised educational system that has been shown to work, but standardisation can encourage mediocrity and stagnation. There is little 'system' incentive for institutions to change their practices and even less personal incentive for individual educators. There is considerable pressure from students, from the universities, from employers, and from accrediting bodies to deliver a certain 'quality' of education. Most engineering academics have no formal teaching qualifications and initially lack confidence in teaching. Almost all will try and avoid failure by replicating their own experience and the experience of their academic peers to guarantee that they 'deliver' a known standard of 'education'. Educators are comfortable with current methods of education; they know what to expect and they believe they can guarantee students acquire a given body of knowledge. Change implies faith in an unproven system. Sticking to what is known is the safe option, and this encourages academics to divert their imagination and effort toward research rather than education:

"Institutions reward good research more than good teaching. Academics have to divide their time between the two activities: the one in which they are professionally qualified and judged by their peers; the other in which they are neither qualified nor judged. Inevitably, research wins." [18]

Engineering academics typically do not have a support structure that encourages them to become reflective practitioners or 'researchers' in teaching. There is no incentive to review education literature or to identify and experiment with new methods of teaching - indeed the opposite is generally true.

Finally, given that the main academic driver is research, the drastic reduction in support for fire research in most parts of the world has resulted in a decreased number of academics with a true competency in FSE research - let alone FSE design practice; it may be argued that good academic researchers do not necessarily make good FSEs or good teachers of design. There is no evidence of a change in this trend despite the important efforts of organizations such as the Fire Protection Research Foundation. Thus, advanced FSE education is in danger of stagnating, reversing, or even disappearing.

\subsection{A Dearth of Exemplars}

A key issue which was identified during the Seminar (with some notably dissenting views) was the relative difficulty of identifying individual exemplars that can be used to demonstrate the iconic aspects of FSE as an engineering discipline. This issue is discussed in detail in Section 8.0.

\subsection{THE SPECIAL ROLE OF THE FIRE AND RESCUE SERVICES}

In most jurisdictions it has historically been the case that ensuring provision of adequate fire safety in buildings was the responsibility of the Architect. This worked reasonably well under a prescriptive FSE framework, since simple rules were able to ensure that the required risk was appropriately accounted for. However, with the advancements of both building and fire safety technologies, most architects no longer have the technical knowledge or requisite skills to adequately address the issues, and this had led to the emergence of the fire safety engineer during the past few decades. However, in many cases the responsibility for fire safety still rests with architects, despite their almost complete lack of technical knowledge in this area. One outcome of this situation is that the role of 'competent authority' in the realm of fire safety is poorly defined in many jurisdictions. During FSE design discussions, or in disputes between consultants, clients, regulators, architects, etc, a situation has arisen wherein the fire brigades - seen by the general public as the custodians of fire safety in the built environment despite not generally having a strictly defined legislative or legal role in the FSE design process - are seen as the de-facto competent authority.

The special role of the fire services as the perceived competent authority was discussed at length during the Seminar, with views expressed by two different fire brigades and also by fire fighter educators at the Scottish Fire Services College where Scottish fire fighters are trained in preparation for service (in addition to ongoing CPD and refresher training). Two key issues were identified: (1) the need for members of the fire services with appropriate knowledge, skills, and attitudes to act as the competent authority in FSE design 
discussions; i.e. the need for FSE graduates within the fire services, and (2) the need for better integration of technical university education with the heuristic knowledge of fire that can only come from observing and interacting with real fire phenomena first hand.

The above suggests that FSE education programmes should seek to develop much closer ties to the fire services, both so as to provide technically competent members of the brigades who can play a defensible role as the competent authority, and as a means by which to enhance the training of FSE graduates, particularly with respect to gaining a heuristic knowledge of fire, an appreciation for the difficulties inherent in fighting real fires in real buildings, and an enthusiasm and excitement for this interesting and complex discipline. The potential benefits to both FSE educators and the fire services are clear.

With respect to the need for FSE graduates within the fire services, the key (and admittedly controversial) issue was deemed to be the current fire service recruitment practices which are used in most jurisdictions and the type and level of training that individuals receive once recruited. It was clear to the participants that if the Fire Services were to sustain a role as a competent authority, it was necessary to define two different types of professionals within the Fire Brigade; (1) those whose primary objective was fire intervention and (2) those devoted to the engineering aspects. While these two objectives are not mutually exclusive, since the experience gained as an operational officer in terms of fire, building and human behaviour can help to maintain 'defensive' FSE competence, this would require different recruitment targets and different training practises. Importantly, a two branch approach would allow the fire services to address issues of retention and compensation for the different groups (i.e. what aspects of the job are more valued?). While this issue is somewhat beyond the scope of the current paper, it is noteworthy that Seminar participants agreed that whatever structure is eventually adopted, if members of the Fire Services are to execute fire engineering roles in design or investigation then the same educational requirements should apply to professionals within or outwith the Fire Services.

\subsection{DOES FSE (EDUCATION) HAVE A PROBLEM?}

Seminar participants were asked to raise any problems that they could see within the FSE community relevant to Education. The following recurring themes were identified (in no particular order):

- Size of the discipline: FSE is a relatively small, niche discipline. Few educational programmes exist, and there is (notwithstanding support from groups such as The LRET) little serious investment in FSE education. A worrying result of this is that in many countries/jurisdictions fire safety 'engineers' with little relevant knowledge or experience are performing detailed designs without the competence (or competency awareness) to do this work. In essence, the relative lack of skilled graduates allows (even requires) poorly qualified people to design. Furthermore, competent dialogue within a technical profession requires a certain quantity of people with the requisite competencies, and this quantity of people does not currently exist in FSE in many jurisdictions.

- Prescription versus performance: The FSE profession exists, and by and large educates, for a technology based rather than a design based world, but the engineering world continues to move towards a performance-based environment where science-based prescription is simply one tool among the many available approaches to meet the performance objectives. There can be a serious problem when FSE designers use a prescriptive mindset in a performance-based world, particularly when they do not understand the fundamental basis of the prescriptive requirements. There is a further problem in that even if the basis of the code requirements are known and understood, the codes typically do not lead to quantifiable levels of safety. This supports the contention that FSE education should focus on fundamentals rather than codes. FSE has what is needed to be part of the performance-based movement, but people need to be educated to think in these terms. In many cases it is no longer sufficient to simply comply with codes; prescriptive guidance cannot always be applied safely in all situations.

- Accreditation: It is widely believed that FSE has an accreditation problem. Many within the community feel that tighter controls are required in order to prevent anyone from practising as a fire safety engineer. Obviously this is linked to education in that formal accreditation of educational programmes is an obvious first step in developing a global baseline of competence in FSE, as occurs in other professional engineering disciplines. It was noted that this issue is better dealt with in some countries than in others. 
For example, in Sweden performance-based codes, rigorous FSE education, and changed recruitment procedures within the fire brigades allow engineers to competently innovate and push boundaries.

- Integration: For many years it has been widely lamented that there is (notwithstanding some notable exceptions) a lack of integration of FSE into the overall building design process, and that FSE is all too often seen as an add-on to existing projects and used to value engineer buildings or solve problems that could have been prevented with lesser cost/impact had FSE considerations been taken into account earlier in the design process. Good FSE design is about challenging ideas and proactively influencing designs from the outset; this can only be done with an engineering, rather than a technician, mindset.

- Feedback: There is insufficient feedback in FSE. Lessons which could be learned from both successful projects and failures (either minor or serious) are rarely fed back into educational programmes (either university or professional), and there is little meaningful feedback amongst the various players in the FSE community (e.g. consultants, regulators, brigades, etc). This is thought to be due to a combination of lack of rigorous education, poor formal definition of the roles and regulatory systems in place, and considerable commercial pressures on FSE designers. Also, the relative rarity of fires in buildings means that completed designs are rarely challenged by the very design fire scenarios assumed in their creation.

- Heuristics: The concept of 'professional judgement' or 'engineering judgement' is pervasive in FSE. There is concern that what constitutes professional judgement is poorly defined and difficult to quantify. Heuristic knowledge is essential for the top FSE designers and design firms when working outside the prescriptive codes. How this experiential knowledge should (or could) be developed within the limited timescales of university FSE programmes or in the early stages of a fire safety engineer's career, is a serious issue both for universities and for the FSE profession. For example, should an FSE programme choose to use limited time in the curriculum to focus on code-compliant design of sprinkler layouts or the fundamentals of fluid dynamics? Presumably the latter, however this question is worth debating.

- Ethics: Teaching professional ethics is now commonplace in most university courses in all disciplines of engineering, notwithstanding the fact that it is usually seen and taught as an add-on. Ethics are rarely integrated into discipline-specific design courses. Because of the youth of FSE as a professional discipline and also because of the current reliance on heuristic knowledge for innovative designs, ethics are particularly important in FSE. This issue is intimately linked to the need for competency awareness amongst fire safety engineers and an awareness of the need for ongoing (often self-directed) education beyond university graduation. A strong ethical foundation will give FSE graduates the confidence to say "no" when being asked to operate outside of their competencies. The prescriptive codes used to tell FSE graduates "no," but modern performance-based design offers no such specific directives. Again, this is where a strong technically based regulatory environment with staff competent in FSE can assist; the 'ethics' issue is equally important to consider for regulators as for designers.

- Quantifying compliance and risk: The concept of 'compliance' is central to FSE, and is invariably defined with reference to available prescriptive requirements. However, in most cases we cannot actually measure compliance. As a result, commercial drivers - i.e. cheaper, not safer buildings - could potentially exert unwanted pressures on FSE. There are apparently real problems in inexpensive, optimized buildings that do not get FSE scrutiny during design. However, some highly scrutinized iconic buildings have failed also. This issue is related to lack of integration, to a poor understanding of what compliance means (i.e. what is the intent of the prescriptive requirement?), and to the lack of a quantifiable definition of what 'safety' is. In many FSE education programmes there is little or no requirement to truly understand the codes and their origins or intents, and critical concepts of risk perception and risk analysis are, in most cases, covered with insufficient detail (if at all).

- Complexity: Many stakeholders in the FSE community are concerned at the level of complexity which is inherent in modern FSE building designs. This complexity is rarely reflected in university curricula, where different aspects of fire safety are often compartmentalized into different courses. Reliance on, and tradeoffs between, active systems, fire stopping, smoke control, pre-knowledge of human behaviour in fire, and sequential systems operating as designed has created buildings for which it is difficult to foresee the true performance in a real fire and thus to define a realistic design challenge for the fire safety strategy. Furthermore, there is growing concern that improper enactment of the fire safety design 
during construction and operation leads to buildings in which the fire risk is fundamentally changed only a few months/years after construction, with little awareness of this reality by building operators or users. Some modern FSE designs may thus be too complex to be maintained.

The outcome of all the above issues is that egalitarian, competent dialogue is difficult between all constituents of the fire safety community. Educational programmes must therefore strive to raise competency awareness and promotion of ongoing personal and professional growth, rather than focus purely on technical knowledge leading only to stagnation. Graduates must be educated in a manner which encourages them to push the limits and question the status quo, however with an appreciation of what is pragmatically possible to achieve and maintain for the life of the project.

\subsection{Refinement or Transformation - Evolution or Revolution?}

Evolution of the FSE industry is dependent on the ability of university graduates to adapt and change in a changing environment. Can the numerous issues discussed thus far be addressed by refinement of the current system, or is a fundamental transformation of the FSE educational system needed?

If the model for fire safety education is based on teaching/training students to apply standard methods to known problems, which seems to be the current focus in many programs, then graduates can hardly be expected to adapt and change continually throughout their career. It is much more likely that this education system will lead to the creation of a generation of specialist graduates who can apply standard solutions. When new or better knowledge is created, syllabi will be adapted to include the new knowledge, and a new generation of specialist graduates will be produced who can apply similar, although slightly improved solutions. This mode of education is sustainable only if graduates rarely encounter fundamentally new problems, i.e. if the solutions taught in universities are the only ones that need to be applied in industry.

Alternatively, universities could focus on educating generalist graduates who are capable of, and actively seek out, evolutionary change. These graduates would use fundamental knowledge to define problems and use prescribed solutions as tools only where directly applicable. In novel situations where unique problems have been identified these graduates would develop new solutions using their deep understanding. This represents somewhat of a transformation in how university educators (and colleagues in industry) view the role of a university education in FSE. The education process should itself be evolutionary, since the environment in which learning takes place affects students' skills and attitudes. Educators must openly accept that optimum solutions that currently exist are not necessarily applicable to the full suite of problems that students may encounter in a future built environment; that they may not be optimal in perpetuity as science and society advance. Educators must focus on knowledge that is applicable in all cases so that students can apply it in any possible scenario.

Competent graduating engineers require both fundamental knowledge and adaptability to produce appropriate solutions to unique problems. The two attributes are interdependent and therefore cannot be acquired in isolation from one another. Thus education should create an environment in which fundamental understanding is acquired within a framework that encourages adaptation. The nature of such an environment will vary significantly over time and between institutions and it is here that a paradox arises; the FSE community needs to define competence and accredit only those professionals who are competent to generate FSE designs, but at the same time it must not attempt to preserve or unduly standardise the educational content or range of application, which will result in its eventual obsolescence.

An education system that embraces these ideas but with content and range of application that continuously change over time to meet the needs of society will be less likely to stagnate and more likely to evolve in a sustainable way. Thus, what is needed is a system transformation followed by continuous refinement or adaptation of content and application as new knowledge is produced. Of course, the FSE community must also require that FSE practitioners also maintain and develop their skills as knowledge advances, or they risk reducing competence with time. Without maintenance and ongoing education, a competent university graduate will soon stagnate and fall behind the best practice.

\subsection{FIRE SAFETY ENGINEERING CURRICULA}


The description of FSE syllabi available today from both industry $[9,19,20]$ and academic institutions (e.g. see the list of colleges and universities provided by the International Association of Fire Safety Sciences at http://www.iafss.org/links/) tend to focus on disciplinary knowledge, rather than on skills and attitudes. These syllabi cover many of the critical elements of fundamental knowledge that are necessary, and thus are excellent complements to this white paper.

A summary of the history of FSE university education is avoided here, and the reader is referred to Magnusson et al. [9] for further discussion on this issue. The focus of the current paper is on the required educational philosophy or framework that is likely to provide the necessary complement to the disciplinary knowledge previously defined. Only a brief summary of the highlights of the prior FSE curriculum 'content' studies is presented here.

\subsection{Current FSE education}

Prior discussions on curricula for FSE education have focused predominantly (although not entirely) on the content or knowledge to be delivered during an FSE curriculum, and have given recommendations on what one might call the requisite technical content. Relatively little attention has been paid to the additional critical philosophical and pedagogical aspects of an ideal FSE education, which the current paper delineates using four knowledge categories: (1) foundational, (2) technical, (3) professional, and (4) intangible. More discussion on this delineation of content is given in Section 7.1.

Probably the most noteworthy example of a detailed proposal for the requisite technical content or "general knowledge framework" in an FSE curriculum is given in a 1995 paper by Magnusson et al. [9], who present a "proposal for a model curriculum in fire safety engineering". Despite now being more than 17 years old, Magnusson et al. begin by touching on many of the issues noted above. For instance:

- the constantly changing and broad subject matter in FSE education are noted;

- it is stated that in a university level education references to a standard should be included only for a critical evaluation and discussion of the document;

- it is suggested that "the main objective of university-level engineering education is to produce engineers capable of solving industrial problems," implying that engineering is about developing new solutions to new problems, rather than applying known solutions to standard problems;

- the delicate and difficult balance between "basic" and "applied" knowledge is noted as being difficult to strike within the limited timescales of a university education;

- it is noted that the specialist training that most university degrees offer is sufficient only for the graduates' first working task; the need for lifelong learning, continuing professional development, and an awareness of societal and ethical aspects are highlighted as being of great importance in FSE education;

- it is estimated (circa 1995) that only about $25 \%$ of practising fire safety engineers in the United States had a Bachelors Degree (or equivalent) in FSE - suggesting that the core competency of the discipline might rightly be called into question; and

- the immaturity of FSE as a distinct engineering discipline, relative to other engineering disciplines, is noted, and ongoing maintenance of the research pipeline on significant problems in the field is stated as being essential to the future of the (still?) emerging discipline.

The report goes on to describe the job description and skill set (framed as knowledge) required of an FSE graduate, placing focus on the stages of a design project from conception through to decommissioning. The "skills set" of an FSE is stated as being made up of three distinct capabilities:

1) identification of fire hazard;

2) identification of fire protection strategies; and 
3) application of risk analysis and identification of the most cost-effective solution to achieve the acceptable level of risk.

The remainder of Magnusson et al. [9] provides detailed descriptions of the various individual "courses" that should form a model curriculum in FSE. How do these ideas stand up to the changing face of the FSE community?

\subsection{Changing Industry, Changing Education}

Other engineering fields (e.g. structural, mechanical, etc.) have reached a point where the problems encountered by engineers in industry already have solutions that have been iterated and optimised; over centuries in some cases. It is assumed in these disciplines that students left to define and solve real engineering problems will eventually reach the same optimized solutions - a process of "re-inventing the wheel." Many university educators view this as a pointless exercise and assume that the existing solutions represent the pinnacle of understanding and cannot be improved. The educators' role then becomes teaching optimised solutions and giving practice in applying them. This situation exists in a mature field in which safety factors have been optimized and the problems are evolving at a sufficiently slow pace that the lifeexpectancy of professional knowledge and tools is long enough to enable the application of a set of well defined methods throughout the professional life of an individual.

In FSE, numerous common problems have been identified, solved, and in many cases optimised. These solutions have been compiled and published, most commonly as building codes but in some cases as design methods. However, many solutions have not been validated, iterated, and optimised for application on all relevant problems. Over the past three decades, innovation in structural design, building management, and material science has created new problems and highlighted cases where known solutions for fire safety can no longer be applied with confidence or do not represent optimised solutions. In this context FSE cannot be defined as a mature discipline because the expected problems will experience significant changes in a period that is much shorter than the life-expectancy of professional knowledge and tools. Thus, the continuous application of well defined methods through the professional life of an individual is not possible; fundamental knowledge and adaptability are paramount.

An alternative approach for FSE is to focus education not on the solution but on the definition of the problem. Knowledge is still required to achieve a solution, but this will be acquired and applied as and when necessary. In this approach students acquire knowledge by doing, and thus at the same time develop the desired skills, and in many cases attitudes. Defining engineering problems encourages students to criticise, create, learn, and use knowledge in order to solve real problems. The knowledge they choose to learn is in a sense up to them, and will be a function of their critical and creative thought, their resourcefulness, and their engineering judgement. In a way, they will learn how to self-define, research, and acquire the 'fundamentals' required by specific design problems.

This problem-based approach to education has been studied in great detail in the literature and has been shown to lead to continuous, lifelong improvement of professionals' core skills [21-27]. Several studies have also structured and presented lists of desirable and transferable skills of graduating engineers that are consistent with this approach $[11,28,29,30]$. For example, critical thinking, creativity and resource investigation are just three examples of skills which are widely acknowledged as being required to produce unique design solutions in any engineering discipline; FSE is no different.

The CDIO initiative, which is an acronym for Conceive, Design, Implement, and Operate [5,30,31,33] provides a comprehensive list of the desirable skills as part of a non-prescriptive framework for designing engineering education programs [30]. The CDIO syllabus takes into account UK-SPEC and US-ABET requirements, as well as industry criteria such as Boeing's 'desired attributes of an engineer' [34]. The skills listed in the syllabus are theoretically transferable across all engineering disciplines and can be adapted using stakeholder surveys [32].

If students are to improve engineering skills identified by the CDIO initiative they must practice conceiving and designing, not just implementing (applying) solutions. Practice cannot be done passively (e.g. attending lectures, reading books, etc). Instead students must actively participate (leading teams, creating new ideas, defining problems, optimising solutions, failing). 
One example of an attempt to embrace the CDIO principles in the FSE education context is the final year undergraduate course in Quantitative Methods in Fire Safety Engineering at the University of Edinburgh. In this course students are presented with a real and current case study - usually a building of unique design for which prescriptive solutions cannot be applied without a dramatic (and negative) impact on the architect's design. Students are requested to define the problems that exist in the structure and, on a weekly basis, to present and defend their chosen solutions. A tutor/guide/coach listens to their defence and critiques the knowledge and reasoning used to justify each proposed solution. As the course progresses, students are expected to collectively use this feedback to iterate, improve, and eventually optimise their solutions.

\subsection{A FUTURE FIRE SAFETY EDUCATION?}

The Magnusson et al. [9] model curriculum ably dealt with the technical knowledge base required of FSE graduates in 1995. At that time, the discipline of FSE had barely emerged, the SFPE handbook had only been in existence for seven years, and the International Association for Fire Safety Science had been operating for only about a decade. In 2012 the technical knowledge basis of FSE remains largely the same, notwithstanding incremental advances in empirical knowledge, major advances in fire and structural modelling capability, and incremental changes both in the practice and regulation of fire safety in the built environment.

Supported by discussions and presentations during The LRET Seminar, we have argued that the technical basis of an FSE degree is not the central issue for discussion, but rather that other attributes of FSE graduates are equally if not more important and that the educational process should reflect these critical needs. It is important to emphasize that we do not claim that definition of requisite technical knowledge is unimportant quite the opposite - we claim that technical knowledge has already been reasonably well defined and that it should thus not be the central issue for discussion. To cover the necessary ground, issues have been divided into: (1) the Content of an FSE curriculum, and (2) the possible Methodologies of teaching.

\subsection{Content}

As noted previously, the content of an FSE curriculum extends beyond the merely technical realm of knowledge, but also includes other desirable attributes of FSE graduates. Seminar participants identified various content desirables which can be grouped into the four categories below.

\subsubsection{Foundational (Background)}

Foundational aspects refer to the requisite knowledge, skills and attitudes of incoming students to an FSE degree. This issue was widely debated during the Seminar, and it is a difficult one for available MSc courses in Fire Safety Engineering where graduates from very diverse backgrounds are accepted into a common FSE curriculum. The level of maths, physics, and chemistry that are needed as a foundation for adequately mastering fluid mechanics, heat and mass transfer, classical thermodynamics, and solid mechanics - seen by Magnusson et al. [9] as the 'background' courses that should form the basis of FSE training - and eventually to adequate mastery of fire fundamentals, enclosure fire dynamics, active and passive fire protection, and human behaviour in fire - seen as the 'fundamental' courses - is difficult to quantify. It was widely agreed by participants that a preparatory science and maths background, such as would be required in any of the classical engineering disciplines, is essential for incoming students to an FSE degree. It should be noted for completeness that Magnusson et al. [9] also suggested two 'applied' courses in their model curriculum: one on risk management and one on industrial fire protection.

Another issue regarding foundational attributes for incoming FSE students was an assertion by some seminar participants that fire safety engineers should have a pre-existing core competency in some other (however related) professional area - i.e. that FSE education should be restricted to post-graduate programmes. This idea arose from discussions around competency awareness where it was noted that possession of core competency is the only way to truly recognize what competency is. This assertion is supported by a wealth of sociological research [17] but suggests that FSE should not be a foundational core competency in its own right. This is admittedly a rather controversial statement, but one which was not debated further during the seminar. 


\subsubsection{Technical (Knowledge)}

Technical knowledge refers to the science-based content required in an FSE curriculum. This has already been discussed in the previous section with respect to the work of Magnusson et al. [9]; the Seminar participants generally agreed that the Magnusson et al. [9] paper still provides an accurate description of the technical requirements (perhaps with the notable exception that computer models can now be expected to play a larger role in essentially all aspects of the curriculum). It could also be credibly argued that structural fire engineering (SFE) knowledge, expertise, and practise have advanced to such a point that a course on SFE should now be included in the FSE model curriculum. However, it is the view of the authors that SFE remains a sufficiently niche sub-discipline that it should be filled by structural engineers with post-graduate training in FSE, despite the fact that FSE graduates will need to understand the fundamental goals and approaches of SFE design.

Most seminar participants spoke at some point about the difficult 'conflict' between the 'fundamentals' of technical FSE knowledge and 'applied' aspects of FSE knowledge. As already noted, this is an age-old conflict that is unlikely to be resolved in the current paper, although it has already been suggested that fundamental knowledge is seen as more important than prescriptive application.

A specific technical area where seminar participants felt that FSE education is particularly lacking (with notable exceptions, such as at Lund University) is in the areas of risk assessment, scenario development, and hazard analysis; in understanding the probabilistic nature of fire and quantifying 'adequate' safety.

It was stated by at least two highly experienced seminar participants that in many countries, such as the United States, FSE curricula are already "way ahead of professional practice in FSE"; implying that more competent FSE graduates, once educated are at risk of entering an FSE profession which is unable to make best use of their advanced knowledge, skills, and attitudes. However, it is our view that this reflects a failing not only on the part of FSE education but perhaps more importantly on the part of the FSE industry. As an example, it can be argued that in countries such as Sweden, where an advanced FSE curriculum at Lund University similar to that described by Magnusson et al. [9] is used to great advantage in training a highly competent national fire service, current industrial practice reflects a higher industry benchmark of FSE training. In these cases better education promotes better industrial and regulatory practices.

\subsubsection{Professional (Skills)}

Here we distinguish professional skills from foundational or technical attributes by the fact that professional skills can only be developed by doing FSE. These are skills in application of knowledge which can be gained only in an experiential way, and as such they are best gained using what many university educators might consider to be non-traditional means. Several potential educational methodologies linked to skills development are discussed below (Section 7.2) with reference to engineering pedagogy. Professional skills are those which allow FSE graduates to be positive and productive members of the FSE community by allowing them to use their foundational and technical knowledge in real professional situations (be they design, regulatory, legal, research oriented, etc). Key examples of professional attributes of immediate relevance to fire safety engineers identified by seminar participants included:

- an ability to apply relevant codes and standards (of course, with a clear understanding of the fundamental objectives and scientific basis of these documents);

- experience in the practical application of FSE (both prescriptive and performance-based, or more likely a combination of the two where prescription is used as a tool within a performance-based mindset);

- a detailed understanding of the legislative and regulatory framework associated with fire engineering (perhaps in more than one jurisdiction);

- a knowledge of the legal and ethical responsibilities of the fire engineer;

- an understanding and practical experience of the FSE design process, ideally both in terms of how FSE design is currently performed by industry and in terms of how it might best be performed by industry;

- initial development of heuristic knowledge and problem solving capability within the context of FSE design and application; and

- clear visual, verbal, and written communication of FSE concepts and designs to both non-technical and technical audiences. 


\subsubsection{Intangible (Attitudes)}

Seminar participants identified a number of interesting, and surprisingly consistent, attributes which can perhaps be best classified as intangibles, since it is by no means clear how such attributes can be developed within FSE curricula other than by embracing these concepts throughout and at all levels of the University system. The most common among these intangibles included:

- well developed abilities in common sense, critical, original, and creative thinking;

- an awareness of competency and having the metacognitive ability to question and recognize competence in oneself and in others (which leads naturally to an inherent desire for self improvement and continuing professional development);

- a positive, flexible, and confident attitude, even in the face of considerable uncertainty and significant knowledge gaps;

- an awareness of the historical evolution and context of FSE as a distinct engineering discipline; and

- the ability and confidence to say "no," and knowing when to say "no" (linked to technical/ethical judgement).

\subsection{Methodologies}

How a student acquires knowledge will determine how they use it in practice. Knowledge acquired in isolation cannot be applied in practice. Method is important. Sections 7.1.1 through 7.1.4 provide a list of the desirable technical knowledge, professional skills, and intangible attitudes that FSE education should seek to impart in its graduates. What can the wider FSE community do to promote attainment of these objectives within FSE educational programmes? The obvious place to start is with the methodologies of education that are used within universities.

Ideally, FSE graduates should be able to identify and define problems and create technically, economically, socially, and environmentally appropriate solutions. The quality of their solutions will depend on both the breadth and depth of their knowledge, and on their skills and attitudes as noted previously. In a perfect world, with motivated students and university faculty who are dedicated to the educational process and to positive learning outcomes for their students, the educational methodologies used within the university would strive to provide:

1) Purpose: An authentic need must be created - a realistic situation from which students are encouraged to identify and define engineering problems, acquire relevant knowledge, and produce potential solutions. The extent to which students go through this process on their own - however with the support of experienced guides and structure - will vary between students but is a prerequisite for deep learning;

2) Autonomy: Students must be given the chance to take responsibility for their learning and their engineering decisions, and to choose their own methods and produce their own solutions as would occur in practice. Thoughtful failures must be lauded and examined rather than punished and ignored; and

3) Structure: Knowledge resources must be delivered in various forms (i.e. traditional lectures, textbooks, videos, websites, etc.) to help those students who would otherwise struggle to solve problems independently, to improve their solutions.

One might argue that the above descriptions are idealistic and that practical application of these principles is difficult within the context of the modern, research-centric university. This is clearly a matter of discussion that goes beyond the scope of this paper, nevertheless examples of potential successful methods of meeting the above goals are reported below for illustration.

\subsubsection{Structure Centred Learning}

It has been postulated herein that knowledge-centric learning is useful when a field is mature but will not be the most effective way of educating professionals in FSE. The attributes of knowledge-centric learning have been studied in great detail showing that the education system that has predominated over the last 50 years 
divides the global engineering process into discrete subjects to be taught as individual courses [35]. Some of these courses are intended to teach the fundamentals (e.g. mathematics, chemistry, fluid mechanics, heat transfer) while other courses teach established methods of applying those fundamentals (e.g. structural design $\&$ analysis, computational modelling, etc.). It is typically hoped that, upon completion of the degree, graduates will be able to synthesise the constituent parts back into a global engineering process.

Students are trained to identify a problem and apply the appropriate method(s) to achieve a solution. They are trained to use established methods, usually through lectures, and then given practice applying those methods to pre-defined problems that converge to a single answer [35]. It is possible to learn these methods without gaining personal experience or contextual understanding, however there would be no way of knowing the consequences of deviating from taught methods. Graduates would have no choice but to apply their knowledge as prescriptive rules. It must be assumed that graduates would very rarely, if ever, encounter a problem for which there is no established method of obtaining a solution.

In keeping with this philosophy, students at university rarely encounter problems for which no established engineering solution already exists, but by one definition 'engineering' is about creating solutions that have never before existed [30]. FSE graduates have little experience in solving new, unique fire safety problems of the type that exist in our modern built environment. Teaching established methods of solving defined problems will not adequately prepare graduates for a career in FSE.

\subsubsection{Purpose Centred Learning}

While professionals in FSE require purpose, autonomy and structure, it is clear that to attain the necessary autonomy required to solve novel problems higher education needs to be centred on purpose. It is the solution to a specific, novel problem that drives the acquisition of contextual knowledge.

The challenge is to encourage students to develop critical thinking and creativity skills to support the application of knowledge to myriad of problem contexts [11,36]. Engineering methodologies contain implicit, sometimes unknown assumptions [37] that may not be appropriate for all cases. The complex nature of fire means that even minor situational changes (e.g. building geometry, ambient conditions) can have a significant impact on the validity of our assumptions and, consequently, on our established methods [39]. Graduates in FSE should be aware that the contextual applicability of established methods and simplifying assumptions has a major impact on the viability of their engineered solutions.

Seminar participants felt that FSE curricula already include a good coverage of the fundamentals as defined by Magnusson et al. [9] and that new graduates tend to be technically competent but lack design skills and an understanding of design context; an observation supported by Todd et al. [39] and The National Academy of Engineering [40]. The CDIO Initiative compiled one of the most comprehensive lists of desirable skills and attributes for engineers from source documents including: ABET EC2000 criteria [41], Boeing's "Desired Attributes of a Graduating Engineer" [34], and two MIT source documents [42,43]. CDIO proposes teaching fundamentals in the context of design and engineering; this is purpose centred learning [30]. Additionally, the Joint Board of Moderators in the UK recognises deficiencies in contextual thinking and proposes that engineering subjects should be taught in the context of design to develop students' abilities to identify, define, and solve complex problems from first principles [44] - seminar participants agreed that this is critical in FSE.

To practically achieve purpose-centred learning, university courses should develop design-oriented courses that encourage students to identify and define problems, develop and evaluate alternative solutions, and affect one or more final designs [45]. Several teaching methodologies have been shown to be effective. For example, Problem-Based learning $(P B L)$ centres on a complex problem that does not have a single, correct answer [21]. Instead, students are encouraged to develop solutions independently. PBL courses have thus far had little impact in mainstream engineering education [46]. One notable example is the University of Maryland Keystone Project course taken by all first-year engineering students [47].

It was debated at the LRET seminar whether university courses based solely on lectures and exams lack engineering and design context, and whether university courses based solely on engineering and design projects lack rigorous training in scientific fundamentals. It was concluded that a combination of the two into 
a single course is clearly optimal. There are numerous examples of courses where this methodology has worked effectively, nevertheless, it needs to be clarified that even in knowledge intensive courses purpose should remain the driving force.

\subsubsection{Learning like Architects - The 'Studio' Environment}

Studio design courses, already used extensively in architecture education, could be modified for use in technical subjects [48]. Architects design, present and then iterate their solution based on feedback from academics or peers. There is no 'right' way to design, however there are scientific and mathematical principles that determine the strength of a design solution. An interesting idea which arose several times during the seminar, particularly given that Architects in many cases remain the custodians of fire safety in the built environment, was that FSE education might benefit considerably from adopting a 'studio' approach to learning in much the same way as architects are educated in the area of architectural design. Studio learning has been shown, both through experience and through scholarly studies, to be an effective means by which to acquire and develop design skills when unique solutions do not exist and where significant unknowns are present from an early stage, as in FSE design. In a studio situation students learn by doing and technical knowledge arises as a consequence of context, rather than as a precondition to context.

Robinson [49] provides a description of studio teaching environments which are widely used in architecture education and discusses how and why the studio is so effective. The parallels with FSE education are striking. Robinson provides the general protocol for studio learning as follows:

1) Students with little formal knowledge of the design process are given a 'design' problem, which is typically only generally defined in relatively loose terms. In FSE, this could be as simple as: develop a fire safety strategy for a given conceptually designed building. This implies that students are expected to do without knowing, and it places the student, rather than the professor/tutor, at the centre of the learning as self-educator (with obvious long term benefits).

2) Each week throughout a semester, students are asked to present to the entire group their ideas, sketches, problems, etc., and the entire group of students (and the professor/guide/tutor) discuss and debate these. The professor/guide/tutor encourages students to re-frame the problem pursue new methods of working out a design solution as required. This requires consolidation of the information they have presented and development of a hierarchy of their ideas.

3) After each student or group has presented their work, the entire group reflects on the key issues of the weekly studio session, and the professor/guide/tutor sets out the next steps.

4) At the end of the semester, all students/groups present their final solutions, and each is constructively critiqued and compared against all other solutions. The professor/guide/tutor then has an opportunity to sum up and discuss any outstanding issues.

This is precisely the approach which has been taken in teaching the course "Quantitative Methods in Fire Safety Engineering" at the University of Edinburgh. The potential benefits of this approach, and the parallels with FSE education, become obvious from the following section of Robinson's [49] paper;

"Each architectural design problem is unique and we therefore have to slowly, over time, accumulate tools to help us to solve these problems, but the solution is not defined and we must therefore be continually critical and reflective in refining our ideas: this is what the design studio is for. It allows for the 'coaching' of students to guide their learning: Students learn by practicing the making or performing at which they seek to become adept, and they are helped to do so by senior practitioners who initiate them into the traditions of practice. The studio replicates conditions similar to those that would be experienced in the profession, but without the practical restrictions of the real world and allows students to work through a programme as they would be expected to do, but without the risks and under guidance... The design studio is an educational model for 'reflection-in-action'. This is to say that students go through particular phases both during and after a tutorial session which helps to build their own understanding, which the tutor 
guides. There is a 'language of design' which students begin to pick up and use from tutors... The design studio gives students a privileged insight into how practitioners act and reflect."

Robinson [49] also discusses the belief that architecture cannot be taught, rather it can only be 'learnt' because one must practice it in order to learn it; "it requires recognition of skilful designing and is holistic in that you must understand the whole in order to understand it at all." It is our contention that the same is true, in most cases, of FSE design. The studio teaching approach suggested above will necessitate a much closer relationship between FSE educators and FSE practitioners, with obvious benefits for both groups and for the education process.

\subsection{WHERE IS MARGARET LAW?}

All well-established engineering disciplines have a deep pool of exemplar projects which can be used during the education of professionals within these disciplines. Indeed, particularly in the early years of an engineering degree it is critical to show students where they might be heading, to promote motivation and excitement, and also to learn technical lessons from the great people and projects, successes and failures of the discipline. For example, in structural engineering university instructors often use the books of the likes of Petroski [e.g. 50,51] to highlight personalities like Isambard Kingdom Brunel or Fazlur Khan, projects like the Brooklyn Bridge or the Eiffel Tower, successes like The Empire State Building or The Burj Khalifa, and failures like the Tacoma Narrows Bridge or the Hyatt Regency walkway collapse. Exemplars are, in some respects, essential in any engineering discipline, both for education and to define the discipline as unique and distinct from others. Who and what are these exemplars in FSE? It is not this paper where the quality and number of these engineering exemplars for FSE will be discussed, rather our view that the discipline needs to do a better job of highlighting our exemplars and explaining to students why they are so meaningful and/or important.

\subsection{People}

Who are the people who define FSE as a unique engineering discipline? Who can be held up as an icon or exemplar? The most obvious example, if we consider true non-prescriptive FSE design, is probably Margaret Law [14], the pioneering FSE researcher and designer who worked with the UK Fire Research Station and subsequently led Arup Fire through the FSE design of such early iconic structures as the Pompidou Centre in Paris and London's Stansted Airport. Margaret Law remains an iconic figure in FSE, and any student of FSE would do well to read as many of her papers and lectures as possible. Law's distinguishing feature was in recognizing the need for knowledge-based innovation in engineering structures for fire, and in using contemporary research to solve practical problems which were preventing the design and construction of innovative structures (in both of the above cases enabling widespread use of unprotected steel and the creation of buildings which have become architectural and social icons). Clearly, we could identify other exemplar personalities; however in comparison to in other engineering disciplines FSE does not manage to distil and bring to the classroom the importance of current engineering achievements. Several names can be extracted from those who developed the engineering discipline of prescriptive fire safety engineering (e.g. Rolf Jensen, etc. [52]). From the research community we can identify Rasbash, Thomas, Drysdale, Kawagoe, Quintiere, etc., and many more, however none of these exemplify practice in the way that we might want to define a distinct engineering profession. We can also look to the fire services and identify the fathers of FSE using names such as Braidwood and Rushbrook, but again there is some question as to whether they could be considered iconic in the context of engineering in the same way as Law. If we look at the FSE profession today, we need to be able to answer, in a classroom, where is Margaret Law? Where is exemplary knowledge-based innovation? Many in the profession will argue that it exists in a magnitude and quality never achieved before. So then why then is it so hard to bring this to the classroom?

\subsection{Projects}

We have already noted the Pompidou Centre (exposed steel) and Stansted Airport (compartmentation and egress distances) as FSE project icons or exemplars, and certainly others exist: The Atlanta Hyatt (atrium design), the Millennium Dome in London (compartmentation and evacuation), the Water Cube in Beijing, and many, many more. However, how many of these are as present in the consciousness of the profession as, for instance, the John Hancock tower in Chicago in Structural Engineering or the Guggenheim Museum(s) in 
Architecture? Can the FSE profession develop a series of exemplar projects that can be used to show the excitement and innovation of the discipline? The answer is probably yes, and it is imperative that we extract from these projects the essence of their innovation and then link the innovations to the tools being taught, so that those entering the field understand how knowledge enabled a transformation.

\subsection{Events}

Many engineering professions are characterized by major events, unfortunately typically disasters, which cause the profession to take a detailed look in the mirror and often result in significant changes in practice and regulation. Certainly this is true in FSE, and the use of failures as learning tools in education has an important place in FSE education. Interestingly, while it is quite difficult in FSE to develop lists of exemplar people and projects and to link them to the specific innovations that they are meant to exemplify (as discovered when this exercise was attempted during The LRET Seminar), it is extremely easy to develop a list of exemplar 'failures' or 'fires' which have had an impact on the profession. Furthermore, in most cases it appeared to be relatively straightforward to establish the specific mistake that lead to the disproportionate nature of the failure. Some of these include (in no particular order): King's Cross, Broadgate Phase 8, Windsor Tower, Telstar House, Triangle Shirtwaist, The Empire Theatre, Piper Alpha, Summerland, numerous tunnel fires (e.g. Mont Blanc), WTC buildings 1, 2, 5, and 7, The great fires of London, Chicago, San Francisco, etc, Bhopal Sandoz, Buncefield, and the list goes on and on. Is it not a worry that, despite the inherent difficulties in demonstrating the successes of fire safety engineering designs, the FSE profession has so many failures to point to, and appears to make so little effort to emphasize its exemplar successes?

It must be concluded that for FSE to provide a true sense of purpose for those studying it, it should better define successes, projects, and people, and clearly identify and emphasize the lessons learned when dealing with failures. Seminar participants agreed that the development of an "exemplars" database and a "lessons learned" centre would be of tremendous benefit to the FSE profession.

\subsection{CONCLUSIONS AND RECOMMENDATIONS}

Performance-based design for fire safety is here to stay. In the words of one of seminar participant, "we cannot go back, the Architects smell freedom." Performance-based design has many acknowledged problems, but paramount among those is the way that we, as a global engineering profession, educate and nurture competent professionals. FSE is an immature discipline, thus it should support holistic, purposecentred education that should place considerable emphasis on learning environments in the form of studios. Technical (fundamental) knowledge is critically important, but it must not be the driving force, and it must not eclipse the development of skills and attitudes essential for the future survival of FSE as a distinct, competency-based engineering discipline. The FSE community must recognize the need for support of both research and educational programs to prevent stagnation of the discipline and reversion to the status of technicians who play little or no creative design role. To positively generate purpose we must generate - out of our successes, our professionals, and our failures - positive exemplars that show the true, exciting, innovative, and complex nature of FSE design. The following are specific recommendations which arose during the seminar.

\section{Academics and Universities}

The universities are, by and large, still educating for a prescriptive world using curricula that were developed some two decades ago [9]. Academics working in FSE programmes should strive to create open-ended design courses which operate in a studio-based format to improve contextual understanding, systems thinking, curiosity, teamwork, creativity and critical thought. Fundamental scientific knowledge should be taught, as much as possible, within context rather than as a precondition to understanding the context; this will help students solve the difficult and ill-defined problems associated with real design projects. Academics should also more actively engage with industry and with the fire services, both to identify deficiencies in graduate skills and knowledge and improve courses accordingly, but also to assure crosseducation in the process (i.e., to push innovation and make best use of graduates' capabilities).

\section{Consultants}

Fire engineering consultancies can significantly improve education, both by directly influencing university curricula and by offering opportunities for exposure of undergraduates to the real world of FSE (through 
undergraduate internships, guest lectures, etc). University curricula can thus be tailored to meet the needs of a knowledge-based FSE industry. Exposing students to 'real world problems' has been shown to increase their motivation and contextual understanding (53). Consultants should strive to operate using a performance-based mindset in which the prescriptive guidance is viewed as a tool in a holistic 'total design for fire' mindset.

\section{Architects}

Architects integrate fire safety into structural design by either consulting fire safety engineers early on or employing them as part of the overall design team. Architecture firms should assist universities in creating architecture-style design courses for fire safety engineers. This will help to produce 'generalist' graduates who understand holistic design, can identify and define fire problems, create novel ideas, present available options, and manage fire specialists. Graduates might then find useful and fulfilling careers within larger, multidisciplinary architectural practices. Architectural practices of all sizes should use their influence with clients to try to make this happen.

\section{Fire Brigades}

Fire brigades should seek to be more involved in university curricula, to assist in creating university courses that develop skills in fire investigation and fire safety auditing for structures, and to provide opportunities for students to develop heuristic knowledge on the behaviour of fire and materials in fire. This should be combined with the creation of a two-tier recruitment system similar to the one employed by the Swedish fire services. This has greatly increased the popularity of the FSE program at Lund University and is considered a good model for promoting and developing the discipline in other countries while also offering tremendous benefit to the fire services and to society at large. The fire service should host both students and academics involved in FSE education. These interactions strengthen relationships and build understanding between various stakeholders in the FSE community. For instance, Lothian \& Borders Fire \& Rescue Service in Edinburgh and the Scottish Fire Services College regularly host undergraduate and masters students and academics from the University of Edinburgh for periods of between one day and six weeks. Experiences such as this have been invaluable to participants who previously had very little understanding of fire fighting procedures and the physical manifestation of fires. London Fire Brigade also offers similar secondment and fire awareness opportunities to academics and professionals and has detached fire engineering qualified fire officers into consultancy practices in order to gain a better appreciation of the design environment, and vice versa.

\section{Research and Professional Organisations}

Regulatory, research, and professional organisations should actively engage with FSE education by reaching out to the world-wide FSE education community with research opportunities of the kind that the Fire Protection Research Foundation, for instance, routinely generates and should adapt at least some of those opportunities to better meet the schedules and needs of a university-based research organization. This will promote strong and direct links between FSE educational programmes and various professional bodies, and will also support university-based academic staff in developing their academic careers as is required by the current global post-secondary education system. Research and professional organizations should also proactively engage with FSE educators to define research needs that might serve as suitable student projects - masters level, independent study, etc - and circulate those to the faculty for their consideration in working with a more hands on curriculum. Professional organizations (e.g. the Institution of Fire Engineers) need to work harder at developing proper accreditation and competency standards within FSE. There is widespread agreement that lack of accreditation remains a damaging and ongoing problem in FSE. Accreditation is a prerequisite to the development of a lasting, defensible, valuable and meaningful professional identity.

\subsection{The Last Word: Karlsson's Key to Success in FSE Education}

As good a place as any to end the discussion is with a series of "keys to success" which were proposed by Prof Bjorn Karlsson during the LRET Seminar in relation to the necessary characteristics of a first class FSE education program. These are food for thought and are as follows:

1) Support for and from research, both basic and multidisciplinary.

2) General demand for graduates in both industry and research.

3) Broad educational scope but with a good technical core curriculum. 
4) Good students.

5) Good staff.

As a discipline, FSE needs to consider if the above keys to success are being met, to what extent, and how they can be supported and nurtured going forward. It is our hope that this white paper will catalyze a badly needed revisiting of FSE educational goals and delivery.

\section{ACKNOWLEDGEMENTS}

The Seminar leading to this white paper was majority funded by The Lloyd's Register Educational Trust (LRET), and we are grateful for the tremendous and unprecedented support provided by the LRET under the direction of Mr Michael Franklin. We would also like to acknowledge the essential intellectual contributions of all of the Seminar participants, listed in Table 1, as well as the considerable in-kind support provided by their respective organizations in allowing each of them to attend. Finally, we would like to thank Gary Stewart at the Scottish Fire Services Training College for providing firefighter training experiences for the seminar participants.

\section{REFERENCES}

[1] W. McClure, T. Bartuska, The Built Environment: A Collaborative Inquiry Into Design and Planning, John Wiley \& Sons, 2007.

[2] L. Han, S. Potter, G. Beckett, G. Pringle, S.H. Koo, G. Wickler, S. Welch, A. Usmani, J.L. Torero, A. Tate, FireGrid: An e-Infrastructure for Next-Generation Emergency Response Support, Journal of Parallel and Distributed Computing, 70 (11) (2010) 1128-1141.

[3] B. Meacham, The Evolution of Performance-Based Codes and Fire Safty Design Methods, NIST-GCR98-761, National Institute of Standards and Technology, USA, 1998, pp. 68.

[4] SFPE, Eng. Guide to Performance-Based Fire Protection, 2nd Edition, Society of Fire Protection Engineers, 2007.

[5] S. Lay, Alternative Evacuation Design for High Rise Buildings, The Structural Design of Tall and Special Buildings, Journal of the Council of Tall Buildings and Urban Habitat, 16 (4) (2007) 487-500.

[6] S.H. Ingberg, Tests of the Severity of Building Fires, Q. Natl. Fire Prot. Assoc. 22 (1928) 43-61.

[7] C. Fleischmann, Is prescription the future of performance-based design? Proceedings of the Tenth International Symposium of the International Association of Fire Safety Sciences, IAFSS, 2011.

[8] S. Schwartz, The Higher Purpose, Times Higher Education, May 2003.

[9] S. Magnusson, et al. A Model Curriculum for Fire Safety Engineering, Fire Safety Journal 12 (1995).

[10] J.W. Prados, Engineering Education in the United States: Past, Present, and Future, ICEE, 1998.

[11] A. Rugarcia, R.M. Felder, D.R. Woods, J.E. Stice, The Future of Engineering Education I. A Vistion for a New Century, Chemical Engineering Education 34 (1) (2000) 16-25.

[12] H. Emmons, The Further History of Fire Science, Combustion Science and Technology 39 (1-6) (1984) 167-174.

[13] H. Hottel, Stimulation of Fire Research in the United States After 1940 (A Historical Account), Combustion Science and Technology, 39 (1-6) (1984) 1-10. 
[14] Arup, Some Selected Papers by Margaret Law, Arup, London, UK, 2002.

[15] P.H. Thomas, Fires and Flashover in Rooms - A Simplified Theory, Fire Safety Journal 3 (1) (1980) 6776.

[16] V. Babrauskas, R.B. Williamson, The Historical Basis of Fire Resistance Testing - Part I, Fire Technology, 14 (3) (1983) 184-194.

[17] D. Dunning, K. Johnson, J. Ehrlinger, J. Kruger, Why People Fail to Recognize Their Own Incompetence, Current Directions in Psychological Science. 12 (3) (2003) 83-87.

[18] D. Laurillard, Rethinking Teaching for the Knowledge Society, EDUCAUSE REVIEW 37 (1) (2002) $16-25$.

[19] National Fire Academy, FESHE Model Curriculum: Pre-Fire Protection Engineering, National Fire Academy, FEMA, 2008.

[20] SFPE, Recommendations for a Model Curriculum for a BS in Fire Protection Engineering (FPE), Society of Fire Protection Engineers (2010) http://eng.sfpe.org/upload/100415 sfpe bs model curriculum final draft.pdf

[21] C. E. Hmelo-Silver, Problem-based learning: What and how do students learn?, Educational Psychology Review 16 (3) (2004) 235-266.

[22] D.R. Woods, Problem-based Learning: How to Gain the Most from PBL, Woods Publishing, Waterdown, Distributed by McMaster University Bookstore, Hamilton ON, 1994.

[23] D.R. Woods, Problem-based Learning: Helping Your Students Gain the Most from PBL, Woods Publishing, Waterdown, Distributed by McMaster University Bookstore, Hamilton ON, 1997 and available on-line at http://chemeng/mcmaster.ca/pbl/pbl.htm.

[24] H.S. Barrows, R. Tamblyn, Problem-based Learning, Springer, New York, 1980.

[25] C.E. Engel, Not Just a Method but a Way of Learning, Chapter 2 in The Challenge of Problem-based Learning, D.J. Boud \& G. Feletieds, Kogan Page, London, 1991.

[26] H.G. Schmidt, (i) Problem-based Learning: Rationale and Description, Medical Education 17 (1983) 11-16; (ii) Foundations of Problem-based Learning: Explanatory Notes, Medical Education 27 (1993) 422.

[27] C. Coles, Is Problem-Based Learning the Only Way? Chapter 30 in The Challenge of Problem-based Learning, D.J. Boud, \& G. Feletti, eds., Kogan Page, London, 1991.

[28] D. Woods, R. Felder, A. Rugarcia, J. Stice, The Future of Engineering Education III. Developing Critical Skills, Chemical Engineering Education, 34 (2) (2000) 108-117.

[29] C. Wise, The Call of the Wild, The Institution of Structural Engineers (2008) 147-152.

[30] E. F. Crawley, J. Malmqvist, \& D. R. Brodeur, The Context in Engineering Education, 4th International CDIO Conference, Gent, 2008, pp. 1-18.

[31] J. Malmqvist, S. Ostlund, K. Edstrom, Integrated Program Descriptions - A Tool for Communicating Goals and Design of CDIO Programs, $2^{\text {nd }}$ International CDIO Conference, Linkoping, Sweden: Linkoping University, 2006.

[32] J. Bankel, Benchmarking Engineering Curricula with the CDIO Syllabus, International Engineering Education, 21 (1) (2005) 121-133. 
[33] K-F. Berggren, CDIO: An International Initiative for Reforming Engineering Education, World Transactions on Engineering and Technology Education, 2 (1) (2003) 49-52.

[34] Boeing, Desired Attributes of an Engineer: Participation with Universities. The Boeing Company, 1996.

[35] R. Felder, The Future of Engineering Education II: Teaching Methods that Work. Chemical Engineering Education , 34 (1) (2000) 26-39.

[36] L.R. Lattuca, P.T. Terenzini, J. Fredericks-Volkwein, G.D. Peterson, The Changing Face of Engineering Education, The Bridge, Summer 2006.

[37] J.L. Torero, B. Lane, The Changing Face of Structural Design for Fire, International Fire Buyers Guide, August, 2004.

[38] G. Rein, J.L. Torero, W. Jahn, et al. Round-Robin Study of a priori Modelling Predictions of The Dalmarnock Fire Test One, Fire Safety Journal 44 (4) (2009) 590-602.

[39] R.H. Todd, C.C. Sorenson, S.P. Magleby. Designing a capstone senior course to satisfy industrial customers. Journal of Engineering Education 82 (2) (1993) 92-100.

[40] National Academy of Engineering, Reforming Engineering Education, Special Issue, The Bridge, Summer 2006.

[41] ABET, Criteria for Accrediting Engineering Programs, Accredication Board for Engineering and Technology, Baltimore, USA, 2003, pp. 24.

[42] E. Crawley, The CDIO Syllabus: A Statement of Goals for Undergraduate Engineering Education, Massachusetts Institute of Technology, Aeronautics and Astonautics. Boston: MIT, 2001.

[43] E. Crawley, Creating the CDIO Syllabus, A Universal Template for Engineering Education, 32nd ASEE/IEEE Frontiers in Education Conference. Boston, MA: Massachussetts, 2002.

[44] JBM, Degree Guidelines, Joint Board of Moderators, London, UK, 2009.

[45] D. L. Evans, G. C. Beakley, P. E. Crouch, G. T. Yamaguchi, Attributes of Engineering Graduates and Their Impact on Curriculum Design, Journal of Engineering Education 82 (4) October 1993.

[46] J.E. Mills, D.F. Treagust, Engineering Education-Is Problem-Based or Project-Based Learning the Answer?, Australasian Journal of Engineering Education, 2003.

[47] K.M. Calabro, K.T. Kiger, W. Lawson, G.M. Zhang, New Directions in Freshman Engineering Design at the University of Maryland FIE '08 Conference Proceedings, Saratoga Springs, NY, October 2008, pp. T2D-6.

[48] D. Kuhn, How do people know? Psycological Science 12 (2001) 1-8.

[49] S. Robinson, Peer Assisted Learning within Architecture: the Methods and Benefits, CEBE Transactions 4 (2) (2007) 43-53.

[50] H. Petroski, To Engineer is Human: The Role of Failure in Successful Design, Vintage, 1985.

[51] H. Petroski, Engineers of Dreams: Great Bridge Builders and the Spanning of America. Vintage, 1995.

[52] J.K. Richardson, (ed.) History of Fire Protection Engineering, National Fire Protection Association, Quincey, USA, 2003. 
[53] T. Litzinger, R. Hadgraft, L. Lattuca, W. Newstetter, Engineering education and the development of expertise, Journal of Engineering Education, 100(1) (2011) 123-150. 